\title{
Perceptions and Understandings on the Need of Change: Viewpoints across Management Levels
}

\author{
Laura Costa Maia*, Rúben Eira, Anabela Carvalho Alves, and Celina Pinto Leão \\ Centro ALGORITMI, School of Engineering, University of Minho, \\ Campus de Azurém, 4804-533 Guimarães, Portugal \\ \{lauracostamaia, eira.ruben\} @gmail.com, \\ \{anabela, cpl\} @dps. uminho.pt
}

\begin{abstract}
The need of change in two Portuguese Textile and Clothing Industry companies is discussed using a qualitative analysis of content transcribed interviews through webQDA. Semi-structured interviews were conducted to several top managements level of both companies. From the interviews it has been possible to understand how the companies intend to contribute to change, their attitudes and perceptions and the benefits expected. The results of this study demonstrated that it is important to involve the different management levels in the process of change. The key-factors that influence change as motivation, involvement, information dissemination for a successfully change were identified as important. However, the findings also show that the interviewees understand that change involves risk and it has both advantages and disadvantages.
\end{abstract}

Keywords: Qualitative analysis; Semi-structured interviews; Textile and Clothing Industry; Lean Production.

\section{Introduction}

According to the Portuguese Textile Association (ATP) clothing, exports grew by over $11 \%$ at the end of the 3rd quarter of 2014, representing $60 \%$ of total exports of the textile and clothing sector. With an export value of $€ 2.1$ billion, the trade balance registered a positive value of $€ 728.2$ million, an increase of $9.3 \%$ compared to the same period of 2013 [1].

Analyzing the Portuguese Textile and Clothing Industry (TCI) by sectors, clothing exports increased $11.4 \%$, the textile products (except home textiles) $9.2 \%$, and home textiles and other textile made-up 5.6\%. Highlighting the increase in exports of felt and rope articles, technical textiles, reaching $€ 27$ million exported, equivalent to a $19 \%$ increase rate. The main client countries (Spain, France, UK and USA) have strengthened their importance, recording an increase between $11 \%$ and $14.7 \%$ [1].

\footnotetext{
* Corresponding author.
} 
Giving these values recently released by ATP, Portuguese TCI, mainly constituted by Small and Medium Enterprises (SME), continues to be a very important sector and still plays an important role in the Portuguese economy. However, it is seen as an industry with cultural barriers, where many continue being small of familiar structure, inhibiting them to gain a higher dimension and a critical mass. Additionally, it is also portrayed as low productivity industry with poor management practices and human resources with low educational level and without the adequate skills from the toplevel to the shop-floor collaborators [2]. This type of industry is, many times, associated with wastes, shop-floor disorganization (Fig. 1) and not valuing people as the main asset.
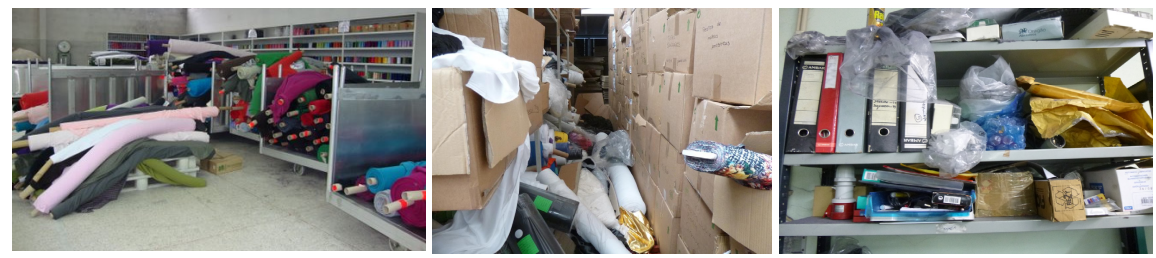

Fig. 1. Examples of wastes and disorganization in TCI

A good organization, waste elimination, good work environment promotion and human potential valorization imply a culture change on the way people think and act. To achieve this change, companies have been used Lean Production principles and tools [3]. Lean Production (LP) is a work organizational model focused on the customer and delivery on time quality products, materials and information without any wastes, i.e., activities that add no value to the products from the customer point of view, respecting people and environment. This means "doing more with less" where less implies less space occupied, less transports, less inventories, and most important, less human effort and less natural resources [4].

To achieve this key idea, Womack and Jones [5] defined Lean Thinking five principles: 1) Value; 2) Value Stream; 3) Flow; 4) Pull System and 5) Pursue Perfection. This last principle implies being always dissatisfied with the status quo and in a continuous improvement (kaizen) eliminates all wastes from processes and services in the organizations. People are the only with skills and capable of doing that so they must be stimulated and their potential valorized. Untapped human potential is considered a waste [6] in a Lean environment.

For a better and successfully implementation of LP in Portuguese TCI, the authors proposed a methodology published elsewhere [7]. Succinctly, this methodology is divided in three phases: 1) preparation of work environment and people; 2) implementation of methodology and 3) evaluation, standardization and sustainability, considering different dimensions: the ergonomic dimension, the sustainability dimension, the operational dimension and the human capital dimension. The first phase is to evaluate if the companies are prepared for change, what they intend to do to perform change, and how they will react to change. If the company is not compromised with Lean Production, and particularly, their top-level management, almost certainly the change will fail. 
In this context, to gather perceptions and understandings concerning this issue, semi-structured interviews to management' levels, namely top, middle and first level, of two textile companies were conducted. Some of the findings are presented and discussed in this paper.

This paper is organized in four sections. After the introduction, it is presented the methodology and method in the second section. Findings analysis and discussion are presented in the third section. Fourth section presents the understandings of the change by both companies, followed by the final remarks in the fifth section.

\section{$2 \quad$ Methodology and Method}

Two TCI companies localized in Vale do Ave in North of Portugal were selected to serve as case studies, designated in this paper as Company A and Company B. One of the companies (Company A) was already the subject of a previous study where some interviews were made and published elsewhere [8], [9] with the intention to understand the need of change. The company B was selected since it is able to embrace to the challenges of change. So, the company accepted a Master Student of Industrial Engineering in order to develop his dissertation there regarding Lean project.

In both companies, keys interviewees were selected to whom the authors conducted the semi-structured interviews: six in Company A and five in Company B. All interviews were performed in a stress-free environment and with complete freedom of expression. An interview guide was developed and used to avoid large deviations to the main objectives of the interviews and to provide reliable, comparable qualitative data. The steps followed in this research are those followed by the authors for company A [8], [9].

\subsection{Research Questions}

The purpose of this qualitative study was to understand and to obtain the answers to three main research questions presented in Table 1.

Table 1. Research questions

\begin{tabular}{ll}
\hline & Research questions \\
\hline Q.1 & "What is the need for change?” \\
Q.2 & "What are the expected results of change?" \\
Q.3 & "What are the suggestions for implementing change?” \\
\hline
\end{tabular}

This set of research questions leads to others, namely: "Is it the first time that participate or is involved, in a change process?"; "Which is the experience of previous changes?" and "How you will participate on this change?". 


\subsection{Interview Design}

The interviews were conducted based on an interview guide. This interview guide include the following topics:

(1) general description of the project (for contextualization purposes);

(2) interviewee social-demographic characteristics and the company characterization;

(3) identification of the purposes of the company (more specific for the company administration);

(4) characterization of the working population;

(5) awareness on the need for change and its causes;

(6) how the managers intend to participate on this change (strategies used);

(7) why the change and how to make this change;

(8) what are the expected outcomes/results; and

(9) suggestions.

The average individual interview length was, more or less, 30 minutes each. All interviews, a total of eleven in both companies, were tape-recorded with the prior approval of the interviewee and confidentiality kept at all times. Then, they were transcribed and sent to the interviewees to validate them. After this, the interviews contents were analyzed using the WebQDA [10].

\subsection{Characterization of the Case Studies}

Company A is a forty-five old company that had an outsized shop-floor space with an annual production of 1000000 units and employed more than 500 employees. It is a multi-national company with French origins and it exports all products that produce. Such as others TCI companies, it suffered from a recent offshore to a low labor wages country. Year after year had been increasing the lowest range products to produce offshore, carrying the large machines to overseas. Nowadays, maintain the same infrastructures most empty, occupying only a quarter of the space with production less than 600000 units annually and employing 162 employees. In the current infrastructures, only produces the high range and more expensive products, keeping the most complex processes indoors such as the remeshing process that demands a high quality and where Portuguese operators has a unique knowledge of that.

Even with a reduced production, the larger infrastructure gives it a "heavy body" that additionally to the long distance corridors needs more than ever, of a better organization to agile the processes and reduces the wastes. So, the company maintains a vast physical space and empty areas waiting for better days where the main challenge will be to attract new clients/projects or captivate the top manager to insourcing the production in Portugal as before. To do this it will need a different mind-set and leanness to become an agile company. This need could be the motive for the openness to change.

Company B is a twenty-five years old company that has, approximately, $4000 \mathrm{~m}^{2}$ distributed by three attached industrial buildings. It is, solely, an export company with 
a monthly production capacity of 200000 units with a few more than 50 employees and, therefore, classified as a SME (Small and Medium Enterprise). Its strategy is to diversify the customer portfolio to face new challenges that allows the company to grow. Also, it is a certified company and has received some awards, increasing in a slow but somewhat stable environment.

This company is, like many others Portuguese companies, strongly family-based structure which, sometimes, brings some problems due to its growing without a proper long-term strategic plan. Also, the disorganization, the number of orders increase without an appropriate space and capacity, the lack of people multi-skilled and the doing business as usual, have become an obstacle to a sustainable growing. So, this company is also open to a change due to the need to adapt to the new challenges like the smaller orders of products diverse. Higher products diversity means a production system capable to deal with this diversity without wastes.

\subsection{Characterization of the Interviewees}

Interviews were focused in management levels of the companies, namely, the top, middle and first level. In Company A, six were interviewed: Chief Executive Office (CEO) and Chief of Production Planning (CPR), (this person assumes both positions), Chief of Technical Office (CTO), Chief of Quality (CQ), Chief of Knitting (CK), Chief of Remeshing (Hand Linking) (CR) and Chief of Human Resources (CHR) (Fig. 2). Detailed analysis of the interviews can be found elsewhere [8], [9].

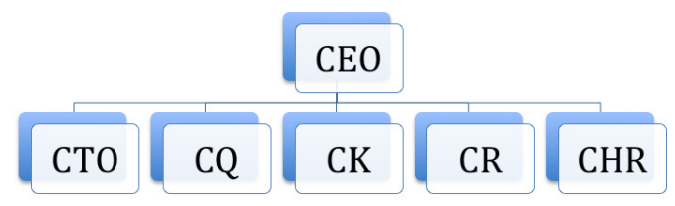

Fig. 2. Functional Organizational Chart Company A

In Company B, due their different functional organizational structure, the number of interviewed chiefs were less, five: CEO/Manager, Chief of Warehouse (CW), Chief of Cutting (CC), Chief of Quality (CQ) and Chief of Production (CP) (Fig. 3).

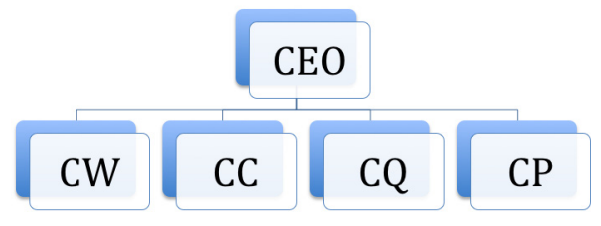

Fig. 3. Functional Organizational Chart Company B

This difference on the functional organizational structure in both companies, representing different sectors, can result in different experiences as well as in different perceptions (or not) concerning change. 
In Company A, 50\% of the interviewees were male and in Company B, all interviewees are male. The average of age of the interviewees in the Company A was approximately 44 years and in Company B approximately 40 years, being the interviewees in company $\mathrm{B}$ in general younger than in Company $\mathrm{A}$, and with less years of working experience. In Company $A$, the majority work more than 10 years in the same working activity and less than 20 in the company. In case of Company B, all interviewees work there less than 10 years, except the CEO/M (25 years) since he is the founder of the company.

\section{$3 \quad$ Findings Analysis and Discussion}

The main objective of this study is to find the answers to the research questions presented in Table 1, based on the results of the semi-structured interviews. Based on the interviews and, also, on the analysis of some reactions of the interviewees during the interviews, of both companies, it was possible to recognize the perceptions and understandings of change from different companies of the same sector. This was inferred from the answers to the main research questions and from secondary questions. For the qualitative data analysis (organization and systematization of data) [10] the authors used the software WebQDA [11].

The data from the interviews was analyzed and codified in key phrases which contains key words such as "improvement"; "need of change"; "involvement"; "benefits"; "difficulties", "changed a lot..."; "need to restructure"; "to be flexible"; "resistance to change". To register the interviews results, it was created a table divided in four dimensions: 1) interview characterization; 2) key phrases of question 1 (Q.1); 3) key phrases of question 2 (Q.2) and 4) key phrases of question 3 (Q.3). Some citations transcribed from the interviews are presented following.

The question Q.1 - “What is the need for change?" - aims to understand if the companies feel the need to change, and the results evidenced this need. This need could be based on the feedback of the collaborators (from top-level management to operators), the customer, or the market. For example, company B mentioned the worldwide liberalization of markets as the trigger that led to an urgent need do implement various structural modifications in the organization. These modifications were necessary to adapt to the fast changes and increasing demands on customer needs, while facing major competitiveness. As mention by the CEO of Company B:

“...our products are products with added value, more demanding customers, and smaller orders and therefore, we have to adjust the organization of the company itself to the reality of what it is now.".

Accordingly, Company A agrees that the change, when needed, should be directed towards customer satisfaction. As referred by CTO:

"First, the company must fit the market.".

Both companies (Company A and B) feel that change is necessary and understand the need for change as a way to improve their performance and face competition.

The question Q.2 - “What are the expected results of change?" - intends to understand how the collaborators plan to participate and facilitate the change, and the 
key phrases indicated, mainly, positive expectations. The CHR of Company A said, "Change is always positive when well justified and well implemented". Additionally, $\mathrm{CW}$ of Company B is prepared to change and he shows interest in being involved in the process: "I'm always ready. Any change (...) I am always available to participate and try, (...) and innovate.". The CQ of Company A pointed out that the process of change, despite its potential benefits, also carries risks that must be taken in account as an introspective moment and learning opportunity: "We can always learn, (...) for good or for bad is always a risk. (...) The change is a risk.".

About one of the secondary questions, 'How will participate on this change', Company A and B feel that it is important to listen to the collaborators and to know what their perspectives are, giving them some autonomy to adapt to change. The teamwork should be promoted so they can overcome their fears and daily challenges and feel supported. For example, from the Company B, the CP said: "Every employee must know they have chiefs that can help when they have a problem. It is easier to lose a minute to ask a question and solve the problem than to ignore it and later have a bigger problem.”.

Everyone must be informed about what happen in the company and about all the changes making the collaborators feel included and being an important part of the process. Regarding this, all the interviewees from Company B emphasized that they use their regular meetings (weekly) between chiefs and workers to inform people about all sort of things, including the changes that are needed and who will go to be affected by them. As mentioned by CQ: "Meetings are always made and it is always said, to whom is necessary, the type of change that will be made.".

The CC of Company B accepted the change, he is open to new ideas and different viewpoints and encourages his workers to do differently if they feel more comfortable that way, as long as the same expected results can be achieved: "... I give them free to do it in another way. Because (...) my opinion is this: if one wants to do it differently, it's ok, since if its suits him better. (...) When they work as they please, is likely to be best done and faster. As long as he gets results, it's alright.".

Another secondary question that aroused during the interviews was about the reactions of the collaborators and their predisposition for and to change. So, it is important to understand how well prepared and motivated they are to change attitudes and to be involved in the process. The CW of Company B considered that, sometimes, people do not readily accept the proposed changes, originating conflicts among workers and their superiors. The CK of Company A stated that changes might promote psychological instability, at least, in a first instance. The resistance to change is commonly seen in the workers since they are very accustomed to working in a certain way and perform the same functions and tasks for long time. Therefore, they feel accommodated in their place with their usual work-schedule routine. As referred by CP from Company B: "It is not easy (...) it is never easy to accept change, it is very complicated. Mostly, people who are accommodated they will always tell you that they were accustomed to working this way during many years and always worked out.". Furthermore, Company B considered change as a benefit to the collaborators because they become polyvalent and prepared to work in anyplace and in any work position. 
The question Q.3 - "What are the suggestions for implementing change?" revealed that people training and involvement are the key-factors. The CR of Company A believes that to a good change implementation it is important to involve the entire company worker's: "I wrap all (...) All together we can improve.". To facilitate the adaptation and understanding of the process of change, CTO from Company A stated that, firstly, it is necessary to change mentalities, the way how people think, and to speak properly with the workers to inform them about the required changes: "Change everything (...) change the mentality (...) First, we have to tell people not to be afraid, to speak and express their views.".

Both companies agree that for a good change, it is necessary to form, inform and involve all the collaborators and that it should be focused on the customer. According to CHR perspective of the Company A, collaborators must be trained and educated to have an open mind: "(...) there must be training (...) there has to be an openness to new things.". Through a learning process, it is possible to shape worker's mindset so they can be more naturally open to new forms of doing their work and new ways of thinking. About this matter, CP of the Company B considered important to have the involvement of all workers in the process of change and that they should be valued (through training and formations) and value their own selves, so they can contribute in the creation process value to the customer. As referred by him: “(...) they will only enhance the company's value if they value themselves (...) with technical training we are trying to achieve that.". To facilitate the process of change, both companies emphasize that it is important to train and listen the employees and give them freedom to adjust to changes.

\section{Case Studies: Understandings of Change}

After gathering and analyzed, the interviews in both companies, it was possible to identify factors highlighted by the interviewees and that, in some way, influence change [9][12]. Comparing the results obtained in both companies it was possible to understand that the factors that most influence change are mutual, except the factor "support from the managers" during and after change referred by Company B (Table 2).

Table 2. Identified factors that influence change in Company A and B

\begin{tabular}{lcc}
\hline Factors that influence change & Company A & Company B \\
\hline Adapt to market challenges & $\checkmark$ & $\checkmark$ \\
Promote communication to all & $\checkmark$ & $\checkmark$ \\
Availability to accept suggestions & $\checkmark$ & $\checkmark$ \\
Motivate all to the change & $\checkmark$ & $\checkmark$ \\
Change mentalities & $\checkmark$ & $\checkmark$ \\
Train people & $\checkmark$ & $\checkmark$ \\
Support from the managers to the change & &
\end{tabular}


The process of change must be adapted to the needs of customers and market. This process should be disseminated by the entire company, and involving all the collaborators to motivate them. Additionally, this should be developed with support of managers during and after the change [12]. This involves risks [9]. This process is more or less difficult according to the level concern of preparation of the company (collaborators). This preparation must be well done and well conducted. To face the natural resistance to change, collaborators must be trained, informed, involved and feel themselves the necessity of change. To lead this process, persons who know, understand and have a good capacity to communicate with employees should be selected. These must be present when they need support, facilitating the understandings of the employees' fears and doubts. Thus change becomes easier.

\section{$5 \quad$ Final Remarks and Future Work}

Independently of the company (A or B) and the interviewee work sector, they all agreed that change is necessary, not only to improve the working environment but also to satisfy the market needs and face competition. Every change has advantages and disadvantages and implies some risks, with more or less resistance.

LP always involves change and because of that, to have a successful implementation is important to prepare the companies to the LP implementation. One of the main goals of LP implementation is to eliminate wastes and produce with less. The waste of human effort is defined as one of the LP waste, and to reduce it, the way people work must change by, for example, increasing their responsibility, motivation and satisfaction [13].

According to the interviews conducted it was possible to verify that only Company A had some knowledge about Lean Production, perhaps due to being a company with over 40 years of experience in the market and with foreign capital. Both companies agree on that they need change and that change must be a process that should be less painful as possible to achieve the main goal: "more with less". It is authors' believe that to implement LP, a good methodology can be the best way to attain it. The receptivity of the different management levels is a very important asset for a good LP implementation.

Acknowledgments. The authors would like to express their acknowledgments to the companies and to all the participants who accepted the challenge to collaborate in this study. The authors are also grateful to national funds by FCT Strategic Project PEst2015-2020, reference UID/CEC/00319/2013.

\section{References}

1. ATP, Associação Têxtil e Vestuário de Portugal (2014), http: / / www . atp.pt

2. ATP, Associação Têxtil e Vestuário de Portugal. Plano Estratégico Têxtil 2020 (2014), http: / /www atp 
3. Alves, A.C., Kahlen, F.-J., Flumerfelt, S., Siriban-Manalang, A.-B.: The Lean Production multidisciplinary: from operations to education. In: International Conference of Production Research Americas (ICPRAmericas), Lima, Peru, July 31-August 1 (2014)

4. Womack, J.P., Jones, D.T., Roos, D.: The machine that changed the world. Rawson Associates, New York (1990)

5. Womack, J.P., Jones, D.T.: Lean Thinking: Banish Waste and Create Wealth in Your Corporation, vol. 10. Simon \& Schuster (2003)

6. Liker, J.: The Toyota Way: 14 Management Principles from the World's Greatest Manufacturer. McGraw-Hill (2003)

7. Maia, L.C., Alves, A.C., Leão, C.P.: Design of a Lean Methodology for an ergonomic and sustainable work environment in Textile and Garment Industry. In: ASME 2012 International Mechanical Engineering Congress \& Exposition (IMECE 2012), Houston, Texas, USA, November 9-15, pp. 1843-1852 (2012)

8. Leão, C.P., Maia, L.C., Alves, A.C.: Needs and Attitudes to Change in Textile and Clothing Industry: A Qualitative Analysis. In: CIAIQ2014 - $3^{\circ}$ 4rd Ibero-American Congress on Qualitative Research, Badajoz, España, July 14-17, pp. 355-359 (2014)

9. Maia, L.C., Alves, A., Leão, C.P.: Perspectivas individuais sobre a necessidade de mudança: estudo de caso na Indústria Têxtil e do Vestuário Portuguesa (Individual perspectivesontheneed for change: a case study in the Portuguese Textile and Clothing Industry). RISTI - Revista Ibérica de Sistemas e Tecnologias de Informação E2(9/2014), 115-127 (2014)

10. Neri de Souza, F., Costa, A.P., Moreira, A.: Análise de Dados Qualitativos Suportada pelo Software WebQDA. In: VII Conferência Internacional de TIC na Educação: Perspetivas de Inovação (CHALLANGES 2011), Braga, Portugal, pp. 49-56 (2011)

11. Miles, M.B., Huberman, A.M.: Qualitative Data Analysis: An Expanded Sourcebook. SAGE Publications (1994)

12. Achanga, P., Shehab, E., Roy, R., Nelder, G.: Critical success factors for lean implementation within SMEs. Journal of Manufacturing Technology Management 17(4), 460-471 (2006)

13. Maia, L.C., Alves, A.C., Leão, C.P.: Sustainable Work Environment with Lean Production in Textile and Clothing Industry. International Journal of Industrial Engineering and Management 4(3), 183-190 (2013) 